\title{
СРАВНИТЕЛЬНЫЙ АНАЛИЗ НОРМАТИВНО-ЗАКОНОДАТЕЛЬНЫХ МЕТОДОВ УЧЕТА И ОПРЕДЕЛЕНИЯ СОСТАВА ЗАТРАТ ПО ПРИКАЗУ № 200, № 1773 И № 334 ПРИ ВЫПОЛНЕНИИ ГОСОБОРОНЗАКАЗА В СФЕРЕ ПРОИЗВОДСТВЕННОГО МАШИНОСТРОЕНИЯ ПРИ УСЛОВИИ КООПЕРАЦИОННОГО ВЗАИМОДЕЙСТВИЯ
}

\author{
(c) 2019 Кислова Екатерина Алексеевна \\ соискатель ученой степени кандидата экономических наук, \\ звание: Исследователь. Преподаватель-исследователь \\ УрФУ им. Б.Н. Ельцина, Россия, Екатеринбург \\ E-mail: Kate.Kislova@gmail.com
}

В статье рассматривается порядок определения состава затрат производства продукции оборонного назначения и анализируется кооперационное взаимодействие выполнения гособоронзаказа.

Ключевые слова: гособоронзаказ, затраты, машиностроение, кооперация.

В современном состоянии мира практически каждый человек знает, что высшей юридической силой каждого действия или бездействия является догма, в нашем случае это закон с его ответвлениями, и разновидностями. Прежде чем начать работу или создать продукт нужно тщательно подготовить почву, создать условия, найти ресурсы и обладать большим опытом и силой воли.

Становление сторон экономики приводит много примеров и изучений, как поэтапно, потихоньку, создавалась эта отрасль и к чему это привело. Экономика - не может быть отдельной графой чего либо, она связывает множество факторов вокруг себя, таких как общество, финансы, философия, наука, культура. Претерпев множество изменений и дополнения, мы имеем ряд сфер экономики: мега экономика, макроэкономика, мезо экономика и микроэкономика. Обратимся к мезо экономике, а точнее к машиностроительной отрасли хозяйствования как способ производственной деятельности предприятий промышленности. Что бы качественно вести дела, и вовремя выполнять гособоронзаказ, нужно тщательно и полностью опираться на законы, следить за их дополнениями, заменами и совместимости оказываемых качественных услуг, а также не допускать простоя и волокиты. Для этого проводят мониторинг и анализ законов, действующего и вновь выпущенного, что бы выяснить что изменилось, что добавлено нового. В ходе изменений определения состава затрат с 08.02.2019 г., вступил новый приказ № 334, который регламентирует более уточнённую и расширенную версию, порядка отнесения затрат, со все возможными исключениями. Старый приказ № 200 от 23.08.2006 г., достаточно давно был принят и изрядно устарел, а также его порядок определения состава затрат от 07.11.2019 г., претерпел изменения и в некоторых местах утратил актуальность. Исходя из данных, автор провел сравнительный анализ Таблица 1.

Не включаются в состав затрат: представительские затраты и денежное довольствие военнослужащих, добровольно-медицинское и пенсионное страхование, превышающие 3\% от суммы расходов на оплату труда, имущество, где организация, продавец и лизингополучатель, балансовых обслуживающих производств и хозяйств не относящиеся к производству.

Сравнительный анализ показал, что для определения состава затрат, в материалах «вспомогательные материалы» включили в графу «приобретение сырья и материалов». В связи с реконструкцией отрасли машиностроения военного назначения, были отдельно созданы графы научно-технической базы, для создания новых технологий, а также систем кооперационного взаимодействия. Новый приказ позволяет отображать в вновь созданных графах все свои новые прорывные технологии, которые ранее либо были разнесены по другим составам, либо заново созданы, например: графы «затраты на изделия собственного производства», «затраты на специальное оборудование для научных (экспериментальных) работ», «затраты на командировки», «затраты по работам (услугам), выполняемым (оказываемым) сторонними организациями», «проценты по кредитам», «административноуправленческие расходы», «трудоемкость», а так 
Таблиц̧ 1. Сравнительный анализ определения состава затрат*.

\begin{tabular}{|c|c|c|}
\hline № П/ח & № 200 от 23 августа 2006 г.[1] & № 334 от 08 февраля 2019 г. [2] \\
\hline \multirow[t]{2}{*}{0100} & \multicolumn{2}{|l|}{ Материальные затраты, в том числе: } \\
\hline & & $\begin{array}{l}\text { позволяют добавить наценки (надбавки) и комиссионные } \\
\text { вознаграждения (работа агента посредника) }\end{array}$ \\
\hline \multirow[t]{2}{*}{0101} & \multicolumn{2}{|c|}{ приобретение сырья, материалов и вспомогательных материалов } \\
\hline & & $\begin{array}{l}\text { вспомогательные материалы, учитываются совместно в } \\
\text { графе с сырьем и материалами }\end{array}$ \\
\hline \multirow[t]{2}{*}{0102} & \multicolumn{2}{|l|}{ приобретение полуфабрикатов } \\
\hline & приобретенное и собственное & только приобретение \\
\hline 0103 & \multicolumn{2}{|l|}{ возвратные отходы } \\
\hline \multirow[t]{2}{*}{0104} & \multicolumn{2}{|l|}{ приобретение комплектующих изделий } \\
\hline & учитывали дополнительные затраты & $\begin{array}{l}\text { не включают расходы, требующие дополнительные затраты } \\
\text { на сборку, отнесли на сторонние затраты }\end{array}$ \\
\hline \multirow[t]{2}{*}{0105} & \multicolumn{2}{|c|}{ оплата работ и услуг сторонних организаций производственного характера } \\
\hline & & $\begin{array}{l}\text { - выполнение отдельных операций по обработке сырья, } \\
\text { материалов и полуфабрикатов } \\
\text { - проведение испытаний по качеству приобретаемых } \\
\text { материальных ресурсов } \\
\text { - сертификация материальных ресурсов иностранного } \\
\text { производства } \\
\text { - доставка готовой продукции заказчику - включаются в } \\
\text { цену вспомогательных работ }\end{array}$ \\
\hline \multirow[t]{2}{*}{0106} & \multicolumn{2}{|l|}{ транспортно-заготовительные затраты } \\
\hline & $\begin{array}{l}\text { - провозную плату } \\
\text { - связанные с заготовкой матери- } \\
\text { алов }\end{array}$ & $\begin{array}{l}\text { - добавлены пункты из прочих производственных: затра- } \\
\text { ты на приобретение, хранение, отпуск продукции } \\
\text { - транспортные услуги по доставке до базисных складов и } \\
\text { перевозкам грузов внутри организации в цеха, склад } \\
\text { - обязательное страхование грузов (сырья, материалов, } \\
\text { полуфабрикатов, и комплектующих) на транспортировку } \\
\text { - командировки с исключением на согласование общих } \\
\text { условий поставки и спецификаций, оформления договоров } \\
\text { на поставку }\end{array}$ \\
\hline \multirow[t]{2}{*}{0107} & \multicolumn{2}{|l|}{ топливо на технологические цели } \\
\hline & приобретенное и собственное & только приобретенное \\
\hline \multirow[t]{2}{*}{0108} & \multicolumn{2}{|l|}{ энергия на технологические цели } \\
\hline & тепловая & $\begin{array}{l}\text { приобретённая/вырабатываемая собственными силами } \\
\text { энергия, с учетом затрат на трансформацию и передачу }\end{array}$ \\
\hline \multirow[t]{2}{*}{0109} & \multicolumn{2}{|l|}{ тара и упаковка } \\
\hline & не было собственного производства & $\begin{array}{l}\text { допускает затраты на производство тары (упаковки) соб- } \\
\text { ственного изготовления }\end{array}$ \\
\hline \multirow[t]{2}{*}{0110} & \multicolumn{2}{|c|}{ затраты на изделия собственного производства } \\
\hline & $\begin{array}{l}\text { В: полуфабрикатах, сторонних ор- } \\
\text { ганизациях, топливе, специальной } \\
\text { оснастке }\end{array}$ & $\begin{array}{l}\text { выделена из статей, кроме энергии, научных работ, тары и } \\
\text { упаковки, а также затраты уникального или эксперимен- } \\
\text { тального изделия, общехозяйственных, а так же если госу- } \\
\text { дарственный заказчик поставляет давальческие материаль- } \\
\text { ные ресурсы, то их стоимость в себестоимости продукции } \\
\text { не учитывается }\end{array}$ \\
\hline 0200 & \multicolumn{2}{|l|}{ Затраты на оплату труда, в том числе: } \\
\hline \multirow[t]{2}{*}{0201} & \multicolumn{2}{|l|}{ основная заработная плата } \\
\hline & $\begin{array}{l}\text { расписана оплата неквалифициро- } \\
\text { ванного работника }\end{array}$ & $\begin{array}{l}\text { добавлены специальные надбавки основных работников } \\
\text { при командировках на территории иностранных государств }\end{array}$ \\
\hline 0202 & дополнительная заработная плата & \\
\hline \multirow[t]{2}{*}{0300} & \multicolumn{2}{|c|}{ Страховые взносы на обязательное социальное страхование } \\
\hline & $\begin{array}{l}\text { единый соц. налог и взносы от проф. } \\
\text { заболевания и несчастных случаев }\end{array}$ & $\begin{array}{l}\text { взносы на социальное, пенсионное и медицинское страхо- } \\
\text { вание, страхование от несчастных случаев и профзаболева- } \\
\text { ний }\end{array}$ \\
\hline
\end{tabular}




\begin{tabular}{|c|c|c|}
\hline 0400 & \multicolumn{2}{|c|}{ Затраты на подготовку и освоение производства, в том числе: } \\
\hline \multirow[t]{2}{*}{0401} & \multicolumn{2}{|l|}{ пусковые затраты } \\
\hline & $\begin{array}{l}\text { могли быть через отдельный кон- } \\
\text { тракт }\end{array}$ & $\begin{array}{l}\text { корректировке проектно-сметной документации по освое- } \\
\text { нию новых производств, с учетом тех. условий }\end{array}$ \\
\hline \multirow[t]{2}{*}{0402} & \multicolumn{2}{|c|}{ затраты на подготовку и освоение новых видов продукции } \\
\hline & $\begin{array}{l}\text { на разработку ТП проектированием } \\
\text { специальной оснастки, инструмен- } \\
\text { тов и приспособлений, организаци- } \\
\text { ей производства не носящий капи- } \\
\text { тальный характер (амортизация) }\end{array}$ & $\begin{array}{l}\text { - на подготовку и освоение новых видов продукции, воз- } \\
\text { обновляемой после 2-х календарных лет и более, и продук- } \\
\text { цию объёмы производства которой увеличилось в } 2 \text { и более } \\
\text { раз, если не были возмещены ранее } \\
\text { - частичное изменение конструкций, модернизацией } \\
\text { деталей, пересмотр технологического процесса за счет } \\
\text { капитальных вложений } \\
\text { - освоение вводимых производственных мощностей в } \\
\text { течении трех лет на единицу продукции } \\
\text { - если период подготовки и освоения производства (менее } \\
\text { года), затраты могут быть включены в ОПз }\end{array}$ \\
\hline \multirow[t]{2}{*}{0500} & \multicolumn{2}{|c|}{ Затраты на специальную технологическую оснастку } \\
\hline & по смете & согласно техническим документам \\
\hline \multirow[t]{2}{*}{0600} & \multicolumn{2}{|c|}{ Затраты на специальное оборудование для научных (экспериментальных) работ } \\
\hline & & $\begin{array}{l}\text { - для приобретения, изготовление, стендов, установок, } \\
\text { испытательных станций, приборов контроля ... } \\
\text { - не учитывается технологическое оборудование в составе } \\
\text { специального оборудования } \\
\text { - определяют на приобретение со стороны (с учетом } \\
\text { транспортно-заготовительных затрат, пошлин, сборов) }\end{array}$ \\
\hline \multirow[t]{2}{*}{0700} & \multicolumn{2}{|l|}{ Специальные затраты } \\
\hline & $\begin{array}{l}\text { незначительные, в общехозяйствен- } \\
\text { ные затраты }\end{array}$ & $\begin{array}{l}\text { в себестоимость пропорционально количеству изделий или } \\
\text { трудоемкости «многолетней» программы выпуска изде- } \\
\text { лий, если возмещение не идет отдельным контрактом, то } \\
\text { отдельной строкой }\end{array}$ \\
\hline \multirow[t]{2}{*}{0800} & \multicolumn{2}{|l|}{ Общепроизводственные затраты } \\
\hline & & $\begin{array}{l}\text { могут формироваться по каждому структурному подразде- } \\
\text { лению }\end{array}$ \\
\hline \multirow[t]{2}{*}{0900} & \multicolumn{2}{|l|}{ Общехозяйственные затраты } \\
\hline & & $\begin{array}{l}\text { - добавлено поддержание гражданской обороны и моби- } \\
\text { лизационных мощностей } \\
\text { - аренду, лицензирование, специальные проверки, стан- } \\
\text { дартизацию, ремонт общего назначения } \\
\text { - предупреждение ЧС } \\
\text { - отчисления использующие радиационно-ядерные объек- } \\
\text { ты (кроме захоронения) } \\
\text { - дезинфекцию } \\
\text { - выставки по презентации продукции } \\
\text { - добровольное медицинское и пенсионное страхование }\end{array}$ \\
\hline \multirow[t]{2}{*}{1000} & \multicolumn{2}{|l|}{ Затраты на командировки } \\
\hline & $\begin{array}{l}\text { в прочих производственных расхо- } \\
\text { дах }\end{array}$ & $\begin{array}{l}\text { - служебные командировки, связанные с авторским сопро- } \\
\text { вождением изготовления продукции } \\
\text { - командировки на территорию иностранных государств } \\
\text { (организация кооперации, заключения договоров) }\end{array}$ \\
\hline \multirow[t]{3}{*}{1100} & \multicolumn{2}{|l|}{ Прочие прямые затраты } \\
\hline & проценты по кредитам & $\begin{array}{l}\text { - опытно-конструкторские и научно-исследовательские } \\
\text { разработки, если ранее не были возмещены }\end{array}$ \\
\hline & & $\begin{array}{l}\text { - страхование риска случайной гибели и повреждения } \\
\text { образцов (комплексов, систем) при создании НТП } \\
\text { - приобретение неисключительного права на использова- } \\
\text { ние программного обеспечения } \\
\text { - лицензирование, сертификация, декларирование соот- } \\
\text { ветствия, поверки и аттестации оборудования } \\
\text { - обращение с радиоактивными отходами } \\
\text { - приобретение и ремонт, восстановление приспособле- } \\
\text { ний общего назначения } \\
\text { - специальной проверке исследованиями в области защи- } \\
\text { ты информации }\end{array}$ \\
\hline
\end{tabular}




\begin{tabular}{|c|c|c|}
\hline \multirow[t]{2}{*}{1200} & \multicolumn{2}{|c|}{ Затраты по работам (услугам), выполняемым (оказываемым) сторонними организациями } \\
\hline & $\begin{array}{l}\text { выделена из прочих производствен- } \\
\text { ных расходов }\end{array}$ & $\begin{array}{l}\text { - затраты по созданию составной части НТП, ремонту и } \\
\text { обслуживанию, при участи выездных бригад } \\
\text { - утилизация (в зависимости от места) }\end{array}$ \\
\hline 1300 & \multicolumn{2}{|l|}{ Производственная себестоимость } \\
\hline \multirow[t]{2}{*}{1400} & \multicolumn{2}{|c|}{ Коммерческие (внепроизводственные) затраты } \\
\hline & & $\begin{array}{l}\text { - услуги вспомогательных цехов по консервации и затари- } \\
\text { ванию готовой продукции } \\
\text { - если затаривание происходит до сдачи на склад готовой } \\
\text { продукции, стоимость тары и упаковки включают в себесто- } \\
\text { имость продукции }\end{array}$ \\
\hline \multirow[t]{2}{*}{1500} & \multicolumn{2}{|l|}{ Проценты по кредитам } \\
\hline & $\begin{array}{l}\text { по ставке рефинансирования (сред- } \\
\text { няя) }\end{array}$ & $\begin{array}{l}\text { - выделена из прочих расходов, не включаются в цену } \\
\text { единицы продукции } \\
\text { - не более суммы ставки центрального банка (минималь- } \\
\text { ная) Российской Федерации на дату расчета плюс 1,5\% } \\
\text { пункта }\end{array}$ \\
\hline \multirow[t]{2}{*}{1600} & \multicolumn{2}{|c|}{ Административно-управленческие расходы } \\
\hline & & $\begin{array}{l}\text { если признаются расходами отчетного периода, в котором } \\
\text { они возникли, и предусмотрено контрактом внесение этих } \\
\text { затрат, в ином случае общехозяйственные }\end{array}$ \\
\hline 1700 & \multicolumn{2}{|l|}{ Себестоимость продукции } \\
\hline 1800 & Прибыль & отображена в статье калькуляции \\
\hline \multirow[t]{3}{*}{1900} & Цена продукции & отображена в статье калькуляции \\
\hline & Технологическая трудоемкость & \\
\hline & $\begin{array}{l}\text { Трудоемкость НТ продукции } \\
\text { (н-ч ч-ч ч-д ч-м) }\end{array}$ & отображена в статье калькуляции \\
\hline
\end{tabular}

* цены, сделанные по приказу № 200, пересмотру не подлежат. Составлено автором с использованием источников $[1,2,3,4]$.

же обязательное отображение граф «прибыль» и «цена продукции». Основной упор сделан на новые графы собственного производства и затраты на подготовку, освоение, развитие методик, программ, технических условий и заданий в ногу с современными технологиями и возможностями.

С экономической стороны, проведенный анализ позволит более точно, подтверждено документально, соотносить суммарную цену продукции оборонного назначения к основанию для не исключения затрат из цены продукции, по всем ее кооперационным ступеням.

Со стороны промышленной кооперация в отличии от предыдущих видов кооперационных сделок, осуществляемых в основном банками, процесс реализуется самими производителями. Формы организации производства, основанные на распределении не только функций между отдельными предприятиями в процессе промышленного производства, но и предметов труда, материалов, но и других законодательных факторов (или этапов).

Сложная работа кооперационного взаимо- действия идет с самых первых шагов создания пакета документов. Перед началом (окончанием) работы любая отрасль производства всегда предоставляет отчет, смету или калькуляцию. Итоговая калькуляция состоит из расшифровки материалов основных и вспомогательных, в том числе собственного производства. Перечень расчетных данных одного товарного изделия состоит из множества строк, доходящих до двух и более тысяч, отображающих его состав, такие как: черные и цветные металлы, отходы, химическая, резиновая, пластмассовая, промышленная продукция, покупные, собственные и комплектующие изделия, акт-заявки и специальные ПКИ, сторонние услуги, а также средства заправки (испытаний), упаковки, погрузки, сопровождения и транспортировки. Вариативность поставщиков, предлагает самые разнообразные стоимостные показатели (в пределах даже одного календарного года), из которых в итоге складывается сумма на заданный период (с учетом коэффициентов и дефляторов, которые периодически тоже имеют место обновляться). После материалов с использованием трудовых показа- 
телей, закрепленных в цехах и проверяемых административным корпусом, рассчитывается заработная плата, и законодательно обязательные отчисления в процентном соотношении (по актуальным нормативам). Добавляются прямо и косвенно-связанные графы по деятельности предприятия (производственные, хозяйственные) и его развития (модернизация, подготовка, освоение, внедрение). В конце выводится себестоимость и прибыль, и итоговая сумма с НДС.

Очень важно составить точное распределение состава затрат по графам, с учетом всех особых условий каждого предприятия каждой ступени кооперации, по статьям без допущения ошибок и погрешностей. Подрядчики и соисполнители по срокам готовности отправляют полный пакет документов, согласно утвержденным спискам требований по законодательным нормам, применимо к данному виду производства продукции, с последующими расчетами. Далее переходят в головное (неподконтрольное) предприятие в прописанные сроки. Достоверность и сроки доставки документов строго регламентируются по видам товара и по перечню (простая почта, для служебного пользователя, секретная). Головное предприятие проверяет расчетные показатели (в бумажном носителе и электронном), степень правильности оформления сопроводительных документов, и форм (введенных и обновляющихся ФАС России). Затем документы проходят этап подписи, и согласования военной приемкой министерство обороны РФ, прикрепленной за данным предприятием на каждом этапе (обычно ВП МО находятся на территории предприятия). Далее этап проверки по инстанциям:

1. Департамент аудита государственных контрактов МО РФ;

2. Федеральная антимонопольная служба РФ;

3. Департамент МО РФ по обеспечению государственного оборонного заказа.

Как будет составлен плановый полный пакет документов, так фактически и реализуется данный проект в рамках и сроках государственного оборонного заказа машиностроительного производства РФ (иных государств), в виде регистрации цены с последующим заключением контракта.

Проведя анализ кооперационного взаимодействия, впоследствии формирования калькуляции затрат, были выявлены существенные проблемы:
- структурная не подчинённость подрядчиков и соисполнителей головному исполнителю, который в свою очередь несет ответственность за проделанную кооперационную с ними работу перед вышестоящими органами власти, в итоге огромная просрочка по временным срокам, срывов заказов;

- не имение санкций и методов воздействия на подрядчиков и их соисполнителей в ускорении работы либо предоставлению полного комплекта документов, согласно нормативным законам, приказам, и иным документам, иными словами - кооперационная независимость;

- монополизация каждого одного промышленного предприятия в данной области технологии, что ведет к ослаблению иммунитета конкурентоспособности, падению выполнения норм и планов качественного производства, косвенного срыва гособоронзаказа;

- устаревшие базы учета материальных продуктов, несвоевременное кооперационное сотрудничество между цехом и административным блоком, ведет к убыткам, и снижению качества выполнения гособоронзаказа.

Всего лишь коснувшись методов учета и определения (отображения) затрат, можно выявить ряд существенно важных кооперационных проблем, связанных с управленческоадминистративной работой как внутри предприятия, так и между головным исполнителем и подрядчиками (соисполнителями).

Предложения методов воздействия по кооперационной структуре [5]:

- закрепить за головным исполнителем административные и иные методы воздействия на подрядчиков (соисполнителей), на этапе заключения, исполнения и закрытия договора (контракта);

- ответственность исполнителя (подрядчика) за свою часть работы перед генеральным заказчиком государственного оборонного заказа РФ - как крайняя мера пресечения;

- ознакомлять и доносить новые формы и законы в определенный период под подпись;

- обязать исполнять в сроки, предусмотренным государственным заказчиком и его исполнителем;

- создать конкурентные условия определения поставщика на этапе закупок;

- создание современных баз (базы), логично устроенных баз кооперационного взаимодействия внутри каждого предприятия. 


\section{Библиографический список}

1. Приказ № 200 от 23 августа 2006 г., об утверждении порядка определения состава затрат на производство продукции оборонного назначения, поставляемой по государственному оборонному заказу.

2. Приказ № 334 от 08 февраля 2019 г., об утверждении порядка определения состава затрат, включаемых в цену продукции, поставляемой в рамках государственного оборонного заказа.

3. Редакция Приказа Минпромторга России № 1773 от 07 ноября 2019 г., Порядок определения состава затрат на производство продукции оборонного назначения, поставляемой по государственному оборонному заказу.

4. Изменения, которые вносятся в порядок определения состава затрат на производство продукции оборонного назначения, поставляемой по государственному оборонному заказу, № 1773 от 7 ноября 2013 г.

5. «Умные контракты» цифрового предприятия при выполнении государственного оборонного заказа в сфере машиностроения, Современная наука: актуальные проблемы теории и практики. Серия «Экономика и право», октябрь 2019 г.-Кислова Е.А. 